University of Wollongong

Research Online

Faculty of Health and Behavioural Sciences -

Papers (Archive)

Faculty of Science, Medicine and Health

$1-1-2006$

\title{
Clinician optimism: Development and psychometric analysis of a scale for mental health clinicians
}

\author{
Mitchell K. Byrne \\ University of Wollongong, mbyrne@uow.edu.au \\ Nichole L. Sullivan \\ Illawarra Institute for Mental Health \\ Stephen J. Elsom \\ Monash University
}

Follow this and additional works at: https://ro.uow.edu.au/hbspapers

Part of the Arts and Humanities Commons, Life Sciences Commons, Medicine and Health Sciences Commons, and the Social and Behavioral Sciences Commons

\section{Recommended Citation}

Byrne, Mitchell K.; Sullivan, Nichole L.; and Elsom, Stephen J.: Clinician optimism: Development and psychometric analysis of a scale for mental health clinicians $2006,11-20$.

https://ro.uow.edu.au/hbspapers/142

Research Online is the open access institutional repository for the University of Wollongong. For further information contact the UOW Library: research-pubs@uow.edu.au 


\title{
Clinician optimism: Development and psychometric analysis of a scale for mental health clinicians
}

\author{
Abstract \\ Clinician optimism is an important factor in achieving treatment outcomes in psychotherapy. Currently \\ there are no measures of mental health clinician optimism which report substantial psychometric \\ validation. This study sought to assesses the validity and reliability of the Therapeutic Optimism Scale \\ (TOS). 223 mental health clinicians working in a range of clinical settings were administered the TOS and \\ convergent and discriminate validity were established. Test-retest reliability was established over a period \\ of one month. The Therapeutic Optimism Scale was found to achieve acceptable reliability (Chronbach's \\ alpha $=.68)$ and yielded consistent scores over a one month period $(r=.68, p<.01)$. Factor analyses \\ revealed a three-factor solution reflecting (1) General Treatment Outcome Expectancy, (2) Personal \\ Treatment Outcome Expectancy and (3) Pessimism. These findings support the utility of the Therapeutic \\ Optimism Scale for research purposes; however further revision is recommended to enhance the \\ reliability of the scale.
}

\section{Keywords}

psychometric, clinician, mental, scale, analysis, development, clinicians, health, optimism

\section{Disciplines}

Arts and Humanities | Life Sciences | Medicine and Health Sciences | Social and Behavioral Sciences

\section{Publication Details}

Byrne, M. K., Sullivan, N. L. \& Elsom, S. J. (2006). Clinician optimism: Development and psychometric analysis of a scale for mental health clinicians. Australian Journal of Rehabilitation Counselling, 12 (1), $11-20$. 


\title{
Clinician Optimism: Development and Psychometric Analysis of a Scale for Mental Health Clinicians
}

\author{
Mitchell K. Byrne and Nichole L. Sullivan \\ University of Wollongong, Australia \\ Stephen J. Elsom \\ Monash University, Australia
}

\begin{abstract}
Clinician optimism is an important factor in achieving treatment outcomes in counselling contexts. Currently, there are no measures of mental health clinician optimism which report substantial psychometric validation. This study sought to assesses the validity and reliability of the Therapeutic Optimism Scale (TOS). 223 mental health clinicians working in a range of clinical settings were administered the TOS and convergent and discriminate validity were established. Test-retest reliability was established over a period of 1 month. The TOS was found to achieve acceptable reliability (Cronbach's $\alpha=.68)$ and yielded consistent scores over a one month period $(r=.68$, $p<.01)$. Factor analyses revealed a 3-factor solution reflecting (1) General Treatment Outcome Expectancy, (2) Personal Treatment Outcome Expectancy, and (3) Pessimism. These findings support the utility of the TOS for research purposes, but further revision is recommended to enhance the reliability of the scale.
\end{abstract}

Historically, science has focused on types of treatments and their differential effects in achieving treatment outcomes (Lambert \& Bergin, 1994). However, there is a growing body of evidence to support the investigation of clinician factors and how they affect the treatment outcomes of patients (Byrne, Deane, \& Coombs, 2005; Byrne, Deane, Lambert, \& Coombs, 2004; Cartwright, 1980; Noble, Douglas, \& Newman, 2001).

Clinician optimism is defined as a 'clinician's self-reported, specific expectancies regarding patient outcomes in a clinical setting'. Optimism facilitates processing of negative information, gives rise to more thorough and flexible cognitive processing and promotes the development of coping and problem solving skills (Aspinwall, Richter, \& Hoffman, 2001). Among clinicians, optimism may predict persistence in service provision (Aspinwall et al., 2001) and reduce the incidence of 'burnout' Bruckner (1979).

Research on optimism has shown that an optimistic outlook is associated with positive health outcomes (Gillham, Shatte, Reivich, \& Seligman, 2001; Jaycox, Reivich, Gillham, \& Seligman, 1994; Peterson, 1995; Seligman, Schulman, DeRuberis \& Hollon, 1999; Yu and Seligman, 2005) and that optimism can be

Address for correspondence: Mitchell K. Byrne, School of Psychology, University of Wollongong, Wollongong, NSW 2522, Australia. E-mail: mbyrne@uow.edu.au 
transferred onto others (van Dulman \& Bensing, 2002). From a clinical perspective, higher levels of clinician optimism can have health benefits for patients equal and is predictive of treatment outcomes (Priebe \& Gruyters, 1995).

Although interventions targeting the enhancement of optimism have been successfully applied to both patient (Peterson \& Bossio, 2001; Reivich \& Gillham, 2003; Seligman et al., 1999) and clinician (Byrne et al., 2004) samples, there is a paucity in the literature explaining how clinician optimism exercises its effects upon the outcomes of therapy. This is particularly true in mental health services and is in part due to the absence of empirically and psychometrically validated measures of clinician optimism. A valid and reliable measure of mental health clinician optimism would enable the exploration of the clinical advantages of optimism, the relationship it has with treatment outcomes and enable identification of clinicians in need of support.

To date, only one measure assessing mental health clinician optimism has been published, the Clinician Optimism Scale (COS; Florentine \& Grusky, 1990). The COS was developed to assess the optimism of mental health clinicians performing case management in the United States (US) and contains six statements against which the respondent rates patients with whom they work (e.g., 'Will remain in the mental health system for the rest of their lives'). Response options are almost all, most, some, few, or none. Designed as a part of a larger 55-item Competency Assessment Inventory (CAI), the COS has not been reported to have been used alone, and the details of its development, construct validation and reliability testing are limited. The COS has yielded acceptable internal consistency $(\alpha=.62)$ with a sample of 86 case managers (Young, Grusky, Sullivan, Webster, \& Podus, 1998) and with a sample of 282 carers for those with severe mental illness $(\alpha=.77)$ (Chinman et al., 2003). The scale has modest test-retest reliability $(r=.3)$ over a period of 2 weeks (Chinman et al., 2003), and although some psychometric validation has occurred, the results were obtained using the 55-item CAI instrument as a whole, which does not validate the COS subscale for use as a stand alone measure of clinician optimism.

A potential alternative to the COS is the Therapeutic Optimism Scale (TOS). The TOS, which was designed to provide a reliable means of measuring mental health clinician optimism, was originally developed by the third author from the work of Bruckner (1979), and was subsequently modified by Byrne and his colleagues (2004) to enable evaluation of clinician change following an intervention to enhance optimism. The TOS consists of 10 items to which respondents rate their agreement on a 5-point Likert scale ranging from strongly disagree to strongly agree (see Table 1, for the full scale). While the TOS has been used in clinical outcome studies (Byrne et al., 2004), the psychometric properties of the TOS have not previously been reported.

This study aims to investigate the psychometric properties of the TOS in order to determine its utility for measuring mental health clinician optimism. As this is the first reported psychometric analysis of the TOS, an exploratory factor analysis will be employed. Test-retest reliability will be assessed across a 1 month period. Convergent validity will be measured against both the COS (Florentine \& Grusky, 1990) and the State Hope Scale (SHS; Snyder et al., 1996), which measures constructs similar to that of optimism (Bryant \& Cvengros, 2004). The construct of self-esteem (in relation to a specific activity) and optimism (in 
general) are proposed to be neutral or orthogonal (Brookner, 1979; Carver $\&$ Scheier, 2003). Hence, it is hypothesised that correlations between scores on the TOS and scores on a measure of self-efficacy (the MABQ-SE; Byrne et al., 2004) will be approaching zero.

\section{Method}

\section{Participants}

Two hundred and thirty-three participants (33.3\% male and $66.7 \%$ female) were recruited from mental health services throughout New South Wales, Australia. The sample was a convenience sample consisting primarily of clinicians from large New South Wales health services. The clinicians worked in a variety of locations, covering rural $(n=26)$, regional $(n=117)$ and metropolitan areas $(n=73)$. The sample included a wide range of professionals, the majority of which were mental health nurses $(n=132)$; but also included psychologists $(n=36)$, occupational therapists $(n=20)$, social workers $(n=18)$ and a variety of other clinicians.

Sixty-one per cent of the sample worked in a community setting, while $30 \%$ worked in inpatient facilities, $4 \%$ in outpatient services and the remainder in multiple settings. The sample ranged in age from 21 years to 61 years with a mean age of 40 years and an average of 12 years experience working in mental health services. Clinicians were mainly treating patients with psychosis $(56.5 \%)$, followed by alcohol and other drug abuse $(27 \%)$.

\section{Measures}

Therapeutic Optimism Scale (TOS). The TOS (Byrne et al., 2004) is a selfreport measure of clinician optimism in respect to the expectations a clinician has about their patient's treatment outcomes. The scale has 10 items measured on a 5-point Likert scale, 4 of which are reverse scored. Potential overall scores on the TOS range from 10 to 50, with high scores indicative of high optimism, and low scores indicative of low optimism.

\section{Medication Alliance Beliefs Questionnaire - Self-Esteem Subscale (MABQ-SE).}

The Medication Alliance Beliefs Questionnaire (Byrne et al., 2004) is a 19-item selfreport measure of clinician beliefs with respect to working with people who have mental health problems. Psychometric analysis (Byrne, Deane, \& Caputi, 2006) has indicated that the scale is reliable $(\alpha=.81)$ and contains five factors: Adequacy; Self Esteem; Work Satisfaction; Empathy; and Pessimism. The Self-Esteem Subscale (MABQ-SE) consists of three statements (e.g., 'On the whole I am satisfied with the way I work with people who have mental health issues'), which the respondent rates on a 5 -point Likert scale ( $1=$ strongly disagree, through to $5=$ strongly agree) with higher scores indicative of higher self-esteem and vice versa. Self-esteem in this case refers to the clinicians' confidence in their ability to achieve positive outcomes when working with people who have 'mental health issues'. Byrne and his colleagues (2006) report that the reliability of the MABQ-SE is modest $(\alpha=.63)$, but reliabilities over 60 have been described as 'acceptable' in the research literature (Aitken, 1997; Murphy \& Davidshofer, 2001).

State Hope Scale. The State Hope Scale (SHS; Snyder et al., 1996) is a six-item self-report measure of hope. The scale is reliable, with alphas ranging from .82 to .95 and has demonstrated convergent and discriminate validity (Snyder et al., 
1996). The SHS was administered in order to provide an additional convergent validity index given the limited psychometric information on the COS.

Clinician Optimism Scale. The COS (Florentine \& Grusky, 1990) is a six-item measure, which assesses clinicians' (case managers) optimism. Statements such as 'Will remain in the mental health system for the rest of their lives' are rated on a 5-point Likert scale ranging from $1=$ almost all to $5=$ none. Using a sample of 49 , the COS was found to have a mean response of 3.33 and a reliability of .58 (Cronbach's Alpha; Florentine \& Grusky, 1990). Information regarding further psychometric properties is limited; however, the instrument has been used in other studies (Chinman et al., 2003; Young et al., 1998).

\section{Procedures}

The survey battery was administered to groups of clinicians during team meetings or handover. The measures were all pen and paper self-report in booklet form, and took approximately 10 minutes to complete. All forms were coded to enable test and retest data matching. A proportion of the data was collected as part of the Medication Alliance research program as per the protocols described by Byrne and his colleagues (2004). Only pretraining TOS and MABQ-SE data were drawn from this source.

\section{Data Analysis}

Reliability analysis and test-retest correlations were employed to establish internal consistency and reliability of the TOS scale. Convergent and divergent construct validity for the scale was assessed using correlations with the COS, the SHS and the MABQ-SE respectively. The data was subjected to factor analysis using the extraction method of principal components, in order to examine the pattern of relationships between items on the TOS. The subscales extracted were then examined for internal reliability. Correlation coefficients were derived for the TOS and its identified subscales, the COS, the MABQ-SE, and the SHS.

Of the 223 cases, 4 were removed due to missing data. Forty-four (20\%) of the total 219 cases were administered the survey battery again at a 1 month followup to provide matched TOS data for test-retest reliability.

\section{Results}

Total scores on the TOS have a possible range between 10 (lower limit) and 50 (upper limit). For this sample, the mean score on the TOS was moderately high at 39.96 with a standard deviation of 4.73 . There was no significant difference in TOS scores when looking at sex, age, profession, year highest qualifications were obtained or practice setting (i.e., inpatient/outpatient/community).

\section{Internal Reliability Analyses}

The reliability analysis for the 10 -item TOS scale $(N=219)$ generated a Cronbach's alpha of .68, indicating that overall, the scale has a modest, yet acceptable level of internal reliability (Aitken, 1997; Murphy \& Davidshofer, 2001).

\section{Inter-Item Correlations}

The inter-item correlations ranged from -.12 to .39, with a mean inter-item correlation of .19. The mean inter-item correlation would ideally be around .3 or higher, 
and when we look at the individual inter-item correlations, they are, on average, unacceptably low indicating several items require revision.

\section{Item-Total Correlations}

Despite the modest level of reliability, the test is discriminating well between respondents and all items show consistency with total test scores. This is evidenced by the item-total correlations all reaching above $r=.3$ except for one item, (item 5, $r=.18$ ).

\section{Item Discrimination}

The low item-total correlation for item 5 indicates that this item is not discriminating between respondents as it only accounts for around $3 \%$ of the total variance in TOS scores. Similarly, item 6 is also not discriminating well between respondents, with mean scores exceptionally high cozmbined with a low standard deviation $(M=4.70, S D=.59)$. This would suggest that items 5 and 6 require revision.

\section{Test-Retest Reliability}

Using matched TOS data from time one and time two $(n=44)$, a significant and relatively strong positive correlation was found between total scores on the TOS at time one and at time two $(r=.68, p<.01)$. Consistent with this, a paired sample $t$ test, found no significant difference between scores at time one $(M=39.96$, $S D=4.74)$ and time two $(M=40.48, S D=5.04)\left(t_{(43)}=.65, p>.05\right)$. The strong correlation between time one and time two scores and the nonsignificant $t$ test, together indicate that the scale is reliable and that clinician optimism is relatively stable over a one month period.

\section{Factor Analysis}

Responses to the items on the TOS $(N=219)$ were submitted to a factor analysis using principal components analysis and a promax (oblique) rotation (see Table 1). The analysis yielded three factors (unforced) with eigenvalues greater than unity and together these three factors account for $55.07 \%$ of the total variance in the observed variable. The three-factor solution was highly robust, as it was replicated when using an alternative extraction method (principle axis factoring) and preserved when only using a random subset of the data $(N=121)$.

Pattern matrix (see Table 1) reveals that five items are loading on Factor 1, three on Factor 2 and two on Factor 3. Interpreting the pattern matrix, the first factor was labelled 'General Treatment Outcome Expectancy', the second 'Personal Treatment Outcome Expectancy' and the third 'Pessimism'.

\section{Construct Validity}

Table 2 shows the relationships between the scales and subscales used in this study. All three factors in the TOS were significantly and positively correlated with overall scores on the TOS. As would be expected, General Treatment Outcome Expectancy correlated the most strongly with overall test scores, followed by Personal Treatment Outcome Expectancy, with the correlation between Pessimism and overall scale scores the lowest. 


\section{TABLE 1}

Item Content, Pattern Matrix and Factor Loadings Yielded Using Principal Components Analysis

Items

Factor 1 Factor 2 Factor 3

1. 'Mental health clinicians have the capacity to positively influence outcomes for people with mental disorders'

2. 'There is little that can be done to help many people with .60 mental disorders'*

3. 'My contribution to positive outcomes is insignificant in comparison to other treatments, for example, medications ${ }^{*}$

4. 'I can make a positive difference to outcomes for most people with mental disorders'

5. 'Positive outcomes are directly related to the quality of mental health clinician skills and knowledge'

6. 'There are always new skills and knowledge I can acquire $\quad .70$ to improve my work'

7. 'The outcome of mental disorders is not significantly affected by clinician interventions'*

8. 'With my assistance most people with mental disorders will recover'

9. 'Often there is little I can do to help people with their mental illness' *

\section{.59}

.66

.66

10. 'Even the most challenging patients can benefit from my intervention'

Note: Rotation method, promax with Kaiser normalisation. *Indicates that the item was reverse scored.

\section{Internal Reliability of the TOS Subscales}

The three identified factors were independently subjected to a reliability analysis. The first subscale, General Treatment Outcome Expectancy, comprised of five items and obtained a Cronbach's alpha of .65. The second subscale, Personal Treatment Outcome Expectancy, yielded a Cronbach's alpha of .58. Finally, the Pessimism subscale (items 2 and 3) obtained a Cronbach's alpha of .44. The low reliability coefficients are likely to be in part a function of the small number of items within the individual scales. Increases in the number of items in a scale falsely inflates the reliability coefficient [30], and thus the smaller the number of items within a scale, the harder it is to achieve acceptable levels of reliability.

\section{Convergent Validity}

The convergent validity section of Table 2 displays the correlation coefficients between the TOS and both Hope and the COS. As expected, scores on the TOS were significantly and positively related to scores on the COS, a similar measure of clinician optimism. Total scores on the TOS were moderately correlated with total scores on the SHS, consistent with the hope and optimism literature (Bryant \& Cvengros, 2004; Carver \& Scheier, 2003; Grusky, Tierney \& Spanish, 1989; Snyder et al., 2001). 
TABLE 2

Correlation Coefficients

\begin{tabular}{|c|c|c|c|c|c|c|c|}
\hline & $\begin{array}{c}\operatorname{COS} \\
n=119\end{array}$ & $\begin{array}{c}M A B Q-S E \\
n=222\end{array}$ & $\begin{array}{c}\text { Hope } \\
n=123\end{array}$ & $\begin{array}{l}\text { Agency } \\
n=123\end{array}$ & $\begin{array}{c}\text { Path } \\
n=124\end{array}$ & $\begin{array}{l}\text { Retest } \\
n=44\end{array}$ & $\begin{array}{c}\text { TOS } \\
n=219\end{array}$ \\
\hline \multicolumn{8}{|c|}{ Construct validity } \\
\hline Total TOS & $.54^{* *}$ & .08 & $.44^{* *}$ & $.44^{* *}$ & $.41^{* *}$ & $.68^{* *}$ & 1 \\
\hline General & $.33^{* *}$ & .10 & $.33^{* *}$ & $.33^{*}$ & $.38^{* *}$ & $.50^{* *}$ & $.80^{* *}$ \\
\hline Personal & $.41^{* *}$ & .09 & $.38^{*}$ & $.38^{* *}$ & $.36^{* *}$ & $.35^{* *}$ & $.70^{* *}$ \\
\hline Pessimism & $.34^{* *}$ & .09 & .13 & .13 & .05 & $.61^{* *}$ & $.61^{* *}$ \\
\hline \multicolumn{8}{|c|}{ Convergent validity } \\
\hline $\cos$ & 1 & .04 & $.35^{* *}$ & $.35^{* *}$ & $.33^{* *}$ & $.43^{* *}$ & $.54^{* *}$ \\
\hline Hope & $.35^{* *}$ & .14 & 1 & 1 & $.75^{* *}$ & $.42^{* *}$ & $.44^{* *}$ \\
\hline Agency & $.35^{* *}$ & .14 & 1 & 1 & $.75^{* *}$ & $.42^{* *}$ & $.44^{* *}$ \\
\hline Pathway & $.33^{* *}$ & .14 & $.75^{* *}$ & $.75^{* *}$ & 1 & .23 & $.41^{* *}$ \\
\hline \multicolumn{8}{|c|}{ Discriminate validity } \\
\hline MABQ-SE & .04 & 1 & .15 & .15 & .14 & .20 & .08 \\
\hline \multicolumn{8}{|c|}{ Test-re-test reliability } \\
\hline Total TOS & & & & & & $.68^{* *}$ & \\
\hline
\end{tabular}

Note: ${ }^{*}$ Correlation is significant at the .05 level (2-tailed).

${ }^{* *}$ Correlation is significant at the .01 level (2-tailed).

TOS $=$ total scores on the Therapeutic Optimism Scale; MABQ-SE $=$ total scores on the Medication Alliance Beliefs Questionnaire - Self-Efficacy Subscale; Hope = total scores on the State Hope Scale; Agency = scores on the agency subscale of the State Hope Scale, Pathway = scores on the Pathway subscale of the State Hope Scale; retest = time two (1 month follow-up) scores for the Therapeutic Optimism Scale

\section{Discriminant Validity}

In order to establish discriminant validity, scores on the TOS were compared to scores on the MABQ-SE. It was posited that clinician optimism and self-esteem, were orthogonal constructs, assuming that optimism can exist divorced of selfesteem. While optimism emphasises the importance of expectancy divorced from causal attribution, self-esteem ascribes outcomes to one's own ability and competencies (Anderson, 2000; Fontain \& Jones, 1997). Scores on the TOS were not related to scores on the MABQ-SE, with the correlation approaching zero. This indicates that the TOS and the MABQ-SE are measuring orthogonal constructs (see Table 2, discriminate validity section).

\section{Discussion}

Results of this study suggest that the TOS comprises three identifiable factors: (1) General Treatment Outcome Expectancy, (2) Personal Treatment Outcome Expectancy, and (3) Pessimism. Overall, the scale had an acceptable level of reliability and produced consistent test scores over a one month period. The TOS exhibited predicted relationships with other indices within its nomological network and these relationships confirm the construct validity of the scale. The measure is not 
sensitive to sex, age, experience or profession, demonstrating its potential utility in a range of mental health settings. These results suggest that although the TOS has acceptable (yet modest) reliability and good construct validity, the reliability of the scale is lower than would be acceptable for clinical purposes.

The three-factor structure of the TOS is potentially contributing to the relatively low reliability seen in these results. Reliability coefficients are a function of how the items are relating to each other and are an indication of how the scale is performing as a whole. However, the factor analysis has revealed that the scale has three components; it is not a pure measure of optimism, rather a multifaceted tool. The TOS tells us generally how clinicians expect treatments to work out for their patients (General Treatment Outcome Expectancy); it tells us how confident the clinician is in their own ability to help the patient achieve good outcomes in therapy (Personal Treatment Outcome Expectancy) and it also tells us about the clinician's tendency to be pessimistic (Pessimism).

For example, Factor 2 is directly related to those items that use personal connotations (e.g., item 8 'With my assistance, most people with mental disorders will recover'). The personal connotations of the statements tap into self-efficacy or the clinician's optimism about their patient's outcomes, which is directly related to their belief in their own ability. While self-efficacy is related to optimism (Ausbrooks, Thomas \& Williams, 1995), optimism tends to be associated with global outcome assessments rather than specific behaviours (Anderson, 2000; Fontain \& Jones, 1997). As such, Factor 2 appears to measure a related but different construct.

The same may be said for Factor 3: Pessimism. Contemporary opinion has identified optimism and pessimism as two distinct constructs rather than opposite poles on the same continuum (Benyamini, 2005; Gillham et al., 2001). This was supported in the present study where Factor 1 and Factor 2 were more strongly related to alternative measures of optimism than was Factor 3 (pessimism).

Factor 1 or General Treatment Outcome Expectancy appears to be measuring optimism as it was operationalised for the purpose of this study, which is 'a clinician's self-reported, specific expectancies regarding patient outcomes in a clinical setting'. Factor 1 incorporates the largest number of items, has the highest eigenvalue, accounts for the greatest proportion of variance in test scores and has the highest reliability coefficient of the three subscales. In general, we would recommend that clinician optimism be measured using a pure scale drawn from Factor 1. Future studies would benefit from an assessment of how the General Treatment Outcome Expectancy subscale would perform in isolation from the other items and would allow for a balance of simplicity against fit to be achieved.

\section{Limitations and Future Directions}

A pragmatic limitation was a result of convenience sampling. Not all of the mental health services that were invited to participate in the study took part, and the study was unable to identify whether staff of these services differed significantly from the final sample on the dependant variable of clinician optimism. The positive skew of the distribution of scores on the TOS is an indication that the sample may be biased toward more optimistic views. As such, caution should be exercised if attempting to use the results of this study as indicative of a normative level of clinician optimism. 
A second limitation was the lack of established measures for comparing and contrasting with the TOS. The study was initiated by an absence of validated measures of clinician optimism. The Clinician Optimism Scale (COS; Florentine \& Grusky, 1990), despite having questionable reliability and validity, was the only available measure of clinician optimism at the time of this study and was thus used to establish convergent validity for the TOS. Although the validity of the COS reduces the strength of this psychometric analysis, it highlights the need for a validated measure of clinician optimism such as the TOS. Despite these limitations, the results are encouraging.

Future research should assess the utility of the TOS for predicting treatment outcomes. If a clinician's early predictions about their patient's outcomes are as accurate as suggested (e.g., Prieb \& Gruyters, 1995), then such predictors should be captured and used in treatment planning. If clinician optimism does in fact have a predictive relationship with treatment outcomes, the assessment of clinician optimism using measures such as the TOS will enable services to identify and rectify the effects of negative clinician beliefs on patient outcomes.

\section{References}

Aitken, L. (1997). Psychological testing and assessment (9th ed.). Boston: Allyn and Bacon.

Anderson, E.H. (2000). Self-esteem and optimism in men and women infected with HIV. Nursing Research, 49, 262-271

Aspinwall, L.G., Richter, L., \& Hoffman, R.R., III. (2001). Understanding how optimism works: An examination of optimists' adaptive moderation of belief and behavior. In E.C. Chang, Ed., Optimism and pessimism: Implications for theory, research, and practice (pp. 217-23). Washington, DC: American Psychological Association.

Ausbrooks, E.P., Thomas, S.P., \& Williams, R.L. (1995). Relationships among self-efficacy, optimism, trait anger, and anger expression. Health Values: The Journal of Health Behaviour, Education and Promotion, 19, 46-54

Benyamini, Y. (2005). Can high optimism and high pessimism co-exist? Findings from arthritis patients coping with pain. Personality and Individual Differences. 38, 1463-1473

Bruckner, F. (1979). Therapeutic optimism: Its components and correlates among clinical social workers, in DSc. Adelphi: Adelphi University School of Social Work.

Bryant, F.B., \& Cvengros, J.A. (2004). Distinguishing hope and optimism: Two sides of a coin, or two separate coins? Journal of Social and Clinical Psychology. 23, 273-303.

Byrne, M.K., Deane, F.P., \& Coombs, T. (2005). Nurse's beliefs and knowledge about medications are associated with their difficulties when using patient adherence strategies. Journal of Mental Health. 14, 513-521.

Byrne, M.K., Deane, F.P., Lambert, G., \& Coombs, T. (2004). Enhancing medication adherence: clinician outcomes from the Medication Alliance training program. Australian and New Zealand Journal of Psychiatry, 38, 246-253.

Byrne, M.K., Deane, F.P. \& Caputi, P. (2006). The Medication Alliance Beliefs Questionnaire: Measuring clinician beliefs and attitudes in relation to mental health clients. Unpublished manuscript.

Cartwright, A.K.J. (1980). The attitudes of helping agents towards the alcoholic client: The influence of experience, support, training, and self-esteem. British Journal of Addiction, 75, 413-431.

Carver, C.S., \& Scheier, M.F. (2003). Optimism. In S.J. Lopez \& C. R. Snyder (Eds.), Positive psychological assessment: A handbook of models and measures (pp. 75-91). Washington, DC: American Psychological Association

Chinman, M., Young, A.S., Rowe, M., Forquer, S., Knight, E., \& Miller, A. (2003). An instrument to assess competencies of providers treating severe mental illness. Mental Health Services Research. 5, 97-108. 
Florentine, R. \& Grusky, O. (1990). When case managers manage the seriously mentally ill: A rolecontingency approach. Social Science Review, 64, 79-93.

Fontaine, K.R., \& Jones, L.C. (1997). Self-esteem, optimism, and postpartum depression. Journal of Clinical Psychology. 53, 59-63

Gillham, J.E., Shatte, A.J., Reivich, K.J., \& Seligman, M.E.P. (2001). Optimism, pessimism and explanatory style. In E.C. Chang, Ed., Optimism $\mathcal{E}$ pessimism (pp. 53-77). Washington, DC: American Psychological Association.

Grusky, O., Tierney, K., \& Spanish, M.T. (1989). Which community mental health services are most important? Administration and Policy in Mental Health. 17, 3-16.

Jaycox, L.H., Reivich, K.J., Gillham, J., \& Seligman, M.E.P. (1994). Prevention of depressive symptoms in children. Behaviour Research and Therapy, 32, 801-816

Lambert, M.J. \& Bergin, A.E. (1994) The effectiveness of psychotherapy. In A.E. Bergin \& S.L. Garfield (Eds.), Handbook of psychotherapy and behaviour change. New York: John Wiley \& Sons.

Murphy, K.R., \& Davidshofer, C.O. (2001). Psychological testing: Principals and applications (6th ed.). NJ: Prentice Hall.

Noble, L.M., Douglas, B.C., \& Newman, S.P. (2001). What do patients expect of psychiatric services? A systematic and critical review of empirical studies. Social Science $\mathbb{E}$ Medicine, 52, 985-998.

Peterson, C. \& Bossio, L.M., Optimism and Physical Well-being. (2001). In E.C. Chang (Ed.), Optimism $\mathcal{E}$ pessimism: Implications for theory, research and practice (pp. 127-145). Washington, DC: American Psychological Association.

Peterson, C. (1995). Explanatory style and health. In G. McClelland Buchanan \& M.E.P. Seligman (Eds.), Explanatory style (pp. 233-246). Hillsdale, NJ: Lawrence Erlbaum Associates.

Priebe, S., \& Gruyters, T. (1995). The importance of the first three days: Predictors of treatment outcome in depressed in-patients. British Journal of Clinical Psychology, 34, 229-236.

Reivich, K.J., \& Gillham, J. (2003). Learned optimism: The measurement of explanatory style. In S.J. Lopez \& C.R. Snyder (Eds.), Positive psychological assessment: A handbook of models and measures (pp. 57-74). Washington, DC: American Psychological Association.

Riskind, J.H., Sarampote, C.S., \& Mercier, M.A. (1996). For every malady a sovereign cure: Optimism training. Journal of Cognitive Psychotherapy, 10, 105-117.

Seligman, M.E.P., Schulman, B.S., DeRuberis, R.J., \& Hollon, S.D. (1999). The prevention of depression and anxiety. Prevention and Treatment, 2.

Snyder, C.R., Sympson, S.C., Michael, S.T., \& Cheavens, J. (2001). Optimism and hope constructs: Variants on a positive expectancy theme. In E.C. Chang (Ed.), Optimism $\mathcal{E}$ pessimism (pp. 101-127). Washington, DC: American Psychological Association.

Snyder, C.R., Sympson, S.C., Ybasco, F.C., Borders, T.F., Babyak, M.A., \& Higgins, R.L. (1996) Development and validation of the State Hope Scale. Journal of Personality $\mathcal{E}$ Social Psychology. 70, 321-335.

van Dulmen, A.M. \& Bensing, J.M. (2002). Health promoting effects of the physician-patient encounter. Psychology, Health $\mathcal{E}$ Medicine, 7, 289-300.

Young, A.S., Grusky, O., Sullivan, G., Webster, C.M., \& Podus, D. (1998). The effect of provider characteristics on case management activities. Administration $\mathcal{E}$ Policy in Mental Health. 26, 21-32.

Yu, D.L. \& Seligman, M.E.P. (2002). Preventing depressive symptoms in Chinese children. Prevention $\mathcal{E}$ Treatment, 5 . 